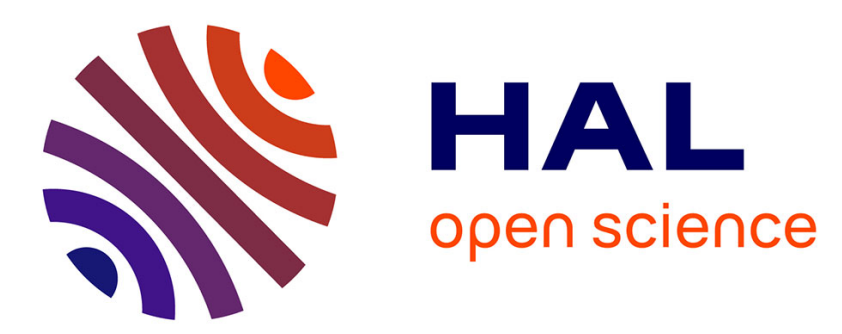

\title{
Iodination of humic acid samples from different origins
}

Pascal E. Reiller, Florence F. Mercier-Bion, N. Gimenez, N. Barré, F. Miserque

\section{To cite this version:}

Pascal E. Reiller, Florence F. Mercier-Bion, N. Gimenez, N. Barré, F. Miserque. Iodination of humic acid samples from different origins. Radiochimica Acta, 2006, 94 (9-11), pp.739-745. 10.1524/ract.2006.94.9-11.739 . cea-00288427

\section{HAL Id: cea-00288427 https://hal-cea.archives-ouvertes.fr/cea-00288427}

Submitted on 16 Jun 2008

HAL is a multi-disciplinary open access archive for the deposit and dissemination of scientific research documents, whether they are published or not. The documents may come from teaching and research institutions in France or abroad, or from public or private research centers.
L'archive ouverte pluridisciplinaire HAL, est destinée au dépôt et à la diffusion de documents scientifiques de niveau recherche, publiés ou non, émanant des établissements d'enseignement et de recherche français ou étrangers, des laboratoires publics ou privés. 


\title{
Iodination of humic acid samples from different origins
}

\author{
By P. Reiller ${ }^{1, *}$, F. Mercier-Bion ${ }^{2, * *}$., N. Gimenez ${ }^{1,2}$, N. Barré ${ }^{2}$ and F. Miserque ${ }^{3}$ \\ ${ }^{1}$ CEA/DEN/DPC/SECR/Laboratoire de Spéciation des Radionucléides et des Molécules, CE Saclay, Bâtiment 391, BP 11, \\ 91191 Gif-sur-Yvette Cedex, France \\ ${ }^{2}$ UMR 8587 "Analyse et Environnement" (CEA/CNRS/Université d'Evry Val-d'Essonne), CE Saclay, 91191 Gif-sur-Yvette Cedex, France \\ ${ }^{3}$ CEA/DEN/DPC/SCP/Laboratoire de Réactivité des Surfaces et Interfaces, CE Saclay, Bâtiment 391, BP 11, \\ 91191 Gif-sur-Yvette Cedex, France
}

(Received August 24, 2005; accepted in revised form March 28, 2006)

\section{Iodine / Humic acid / Iodination / Kinetics / Aromaticity / $U V$-visible / XPS}

Summary. The iodination of Gorleben and synthetic humic substances (HS) was studied complementarily by UV-visible and X-ray Photoelectron Spectroscopy (XPS). The $\mathrm{I}_{2}$ (aq) consumption kinetics could neither be linearly correlated to $\left[\mathrm{H}^{+}\right]$ nor to HS concentration as already observed in the literature. Nevertheless, the electrophilic substitution mechanism was further evidenced by the production of both $\mathrm{I}_{3}^{-}$and $\mathrm{I}^{-}$, leading to a covalent bonding. The XPS analysis of the iodinated samples confirmed the covalent bonding between iodine and carbon of HS for all the samples.

\section{Introduction}

Radioisotopes of iodine $\left({ }^{125} \mathrm{I},{ }^{129} \mathrm{I},{ }^{131} \mathrm{I}\right)$ are important radionuclides in nuclear safety as they represent one of the most significant release from a reactor accident, and for their toxicological impact [1-3]. From the French radioactive waste management point of view, $71 \%$ of the total ${ }^{129} \mathrm{I}$ inventory is part of the high level waste and $29 \%$ is part of the intermediate level waste. Iodine is considered as mobile because it is neither (or poorly) controlled by solubility nor sorbed on any mineral phase under geological conditions considered [4]. Most of iodine intake occurs by drinking water [5], and therefore assessing the bioavailability of dissolved iodine is essential.

The interaction of iodine with natural dissolved organic matter in general and with humic substances (HS) in particular, has been the subject of numerous studies. It has come to a consensus that in soils as well as in aquatic systems, the speciation of iodine is closely related to the redox potential of the medium. In oxidizing media, as in sea water or upper horizons, the major part of iodine is found in iodate form $\mathrm{IO}_{3}{ }^{-}$, whereas in reducing media, iodide $\mathrm{I}^{-}$is the major specie. It has been demonstrated that $\mathrm{I}^{-}$do not interact with HS [6,7]. Nevertheless, it has been shown that in some cases, organically bound iodine can dominate the

\footnotetext{
*Author for correspondence (E-mail: pascal.reiller@cea.fr).

**Present address: IPN - 15, rue Georges Clemenceau, 91406 Orsay Cedex
}

speciation either as methyl iodide [8] or bounded to humic substances [5,9-12]. It is now also clear that this reactivity is closely related to the occurrence of molecular iodine $\mathrm{I}_{2}(\mathrm{aq})$, and its disproportionation to $\mathrm{HIO}$ and $\mathrm{I}^{-}$, either after reduction from $\mathrm{IO}_{3}{ }^{-}$[13] or after oxidation of $\mathrm{I}^{-}[7,12]$.

In fact, the reaction scheme can be viewed as an electrophilic substitution of hydrogen by iodine atom on a phenolic ring [14]. This reaction is well known to lead to trihalomethane $[15,16]$. This scheme has been validated in the case of HS on different samples [6,17], and the covalent character of this interaction has been shown using electrospray ionization mass spectroscopy (ESI-MS) [18], X-ray photoelectron spectroscopy (XPS) [19-21] and in X-ray absorption spectroscopy [22, 23].

Few XPS publications are available in the field of HS studies [24-27]. The literature concerning the XPS investigation of iodine compounds is very limited, except the studies of Bernede et al. [28] concerning the characterization of electrochemically synthesized polycarbazole post-doped with iodine. The lack of papers concerning the spectroscopic characterization of HS and iodine is probably due to the analytical difficulties induced by the sensitivity under beam of the organic matter and of the halogen compounds.

Nevertheless, in some of the latter studies, the characterization of the final reaction products did not satisfied the authors completely as total separation from $\mathrm{I}^{-}$could not be achieved. Thus, further studies were undertaken using other samples: natural humic and fulvic extract from Gorleben (Gohy 573) and synthetic samples. Dialysis procedures were envisaged to improve the incomplete separation between the colloidal humic matter and the iodide ions either none reacted or produced by the reaction [6]. The iodination kinetics was followed in UV-visible spectrophotometry and XPS was used to determine the chemical environment of fixed iodine.

\section{Materials}

\subsection{Samples}

Humic and fulvic acids from Gorleben deep borehole Gohy573 were obtained from Manfred Wolf (GSF-Forschungs- 
zentrum für Umwelt und Gesundheit $\mathrm{GmbH}$, Germany), and synthetic samples were obtained from Susanne Sachs (Forschungsentrum Rossendorf e.V., Germany), through European project Humic Substances in Performance Assessment of Nuclear Waste Disposal: Actinide and Iodine Migration in the Far-Field (FIKW-CT-2001-00128 HUPA). Characterizations of these humic substances are available in $[29,30]$. The samples were used as received and no further purification was done. Weighted samples were dissolved in $10^{-4} \mathrm{NaOH}(\mathrm{pH} \approx 10)$ in order to obtain a thorough dissolution of HA, to minimize the alkaline hydrolysis [31], and to have all samples in the same conditions before iodination procedure.

The stock saturated solutions of $10^{-3} \mathrm{~mol} / \mathrm{L} \mathrm{I}_{2}$ (aq) [32] were prepared from bisublimed iodine (Prolabo). NaI was obtained from Merck. As iodination procedure are somewhat different from one experiment to another they will be described all through the following text.

\subsection{Analytical techniques}

\section{UV-visible spectrophotometry}

UV-visible absorption data were obtained using a Cary 1 spectrophotometer (Varian). As in previous studies [6, 17], kinetics of consumption of iodine by HS was monitored through the decrease in UV-visible absorbance of triiodide complex $\left(\mathrm{I}_{3}{ }^{-}, \lambda=351 \mathrm{~nm}\right)$ using mixes of $\mathrm{I}^{-} / \mathrm{I}_{2}(\mathrm{aq})$. The stock solution of tri-iodide complex was composed of a saturated solution of iodine $2.66 \times 10^{-3} \mathrm{M}$, and $2.6 \times 10^{-2} \mathrm{M}$ of $\mathrm{NaI}$ (Merck) in $0.1 \mathrm{M} \mathrm{NaClO}_{4}$ (Prolabo) as background electrolyte. Formation of $\mathrm{I}_{3}{ }^{-}$occurs through the following reaction [32]:

$$
\mathrm{I}^{-}+\mathrm{I}_{2}(\mathrm{aq}) \rightleftarrows \mathrm{I}_{3}^{-}, \quad K=723
$$

\section{X-ray Photoelectron Spectroscopy (XPS)}

The XPS experiments were carried out with a VG Instruments $^{\circledR}$ 220i spectrometer, using a none monochromated Al $K_{\alpha}$ X-ray source (incident energy: $1486.6 \mathrm{eV}$ ). A source power of $15 \mathrm{kV}$ and of $20 \mathrm{~mA}$ was used. The dimensions of the X-ray beam were approximately $8 \mathrm{~mm}$ per $7 \mathrm{~mm}$. The analysis chamber pressure was in the range of $10^{-8}$ Torr. The binding energy (BE) resolution of the spectrometer was estimated to $0.2 \mathrm{eV}$. To avoid the degradation of the organic matter with the electron flood gun, no charge compensation was achieved during the XPS experiments and so all the BE values were corrected using the $\mathrm{C} 1 s$ signal of contamination carbon at $285 \mathrm{eV}$.

\section{Results and discussion}

\subsection{UV-visible spectrophotometry}

Firstly, the reaction pattern of the samples was verified. The kinetics of the triiodide absorbance decrease caused by iodine consumption by Gohy $573 \mathrm{HA}$ and $\mathrm{FA}$ at $\mathrm{pH}=5$ and $\left[\mathrm{NaClO}_{4}\right]=0.1 \mathrm{M}$, are reported in Fig. 1. Absorbance decrease is somewhat faster than in the previous studies on Mol and Aldrich samples [6]. As in previous cases, the kinetics cannot be linearalised in first order relative to $\mathrm{pH}$, as it is the case for phenolic derivatives $[14,17]$. Even if one could argue that all the phenolic moieties could not react with exactly the same kinetic, theory of kinetics teaches us that a sum of first order leads to an apparent first order kinetics. This was not observed here. Previous experiments have also shown that this reaction is influenced both by ionic strength and iodide concentration [6]. This may indicate that a potential barrier is to be overwhelmed as the negative potential of HS aggregates repels $\mathrm{I}_{3}{ }^{-}$. As a matter of fact, negative potential of humic aggregates increases when ionic strength decreases [33]. Hence, we can postulate that the kinetic control of the substitution reaction is not limited by the substitution reaction itself but rather by the approach of "reactive sites" by iodine.

The same experiments were performed on synthetic samples M1 and M42. Kinetic patterns are even faster than those of natural humic samples, as displayed in Fig. 2. Kinetics of the different samples can be compared in Fig. 3 as they were acquired in comparable conditions at $\mathrm{pH}=5$, except for the Mol sample $(\mathrm{pH}=6)$. It can be seen in Fig. 3 that kinetics increase from Aldrich to M42 samples. This behaviour can be related to the elementary ratio $\mathrm{H} / \mathrm{C}$, which in turn can be related to the aromaticity of the humic sample. $\mathrm{The} \mathrm{H} / \mathrm{C}$ ratios calculated from the elementary compositions of these samples are reported in Table 1. Hence, the increase of the iodination kinetics can clearly be related to

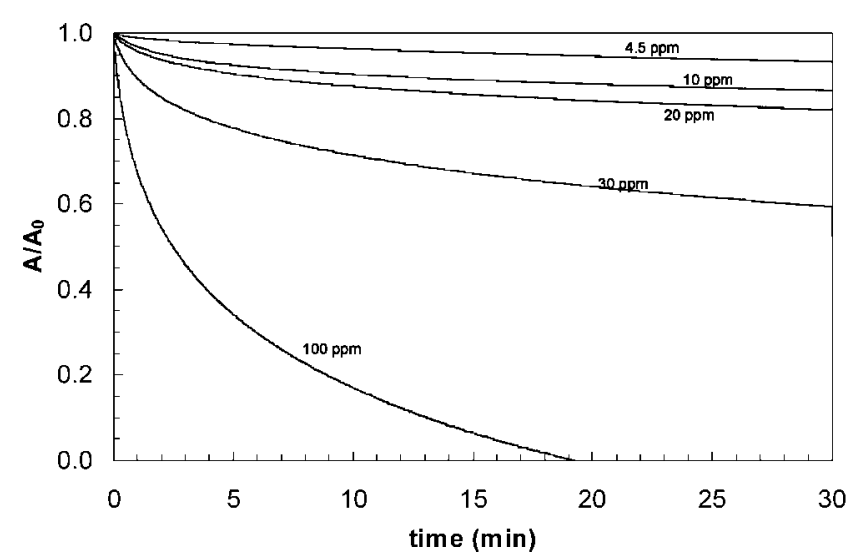

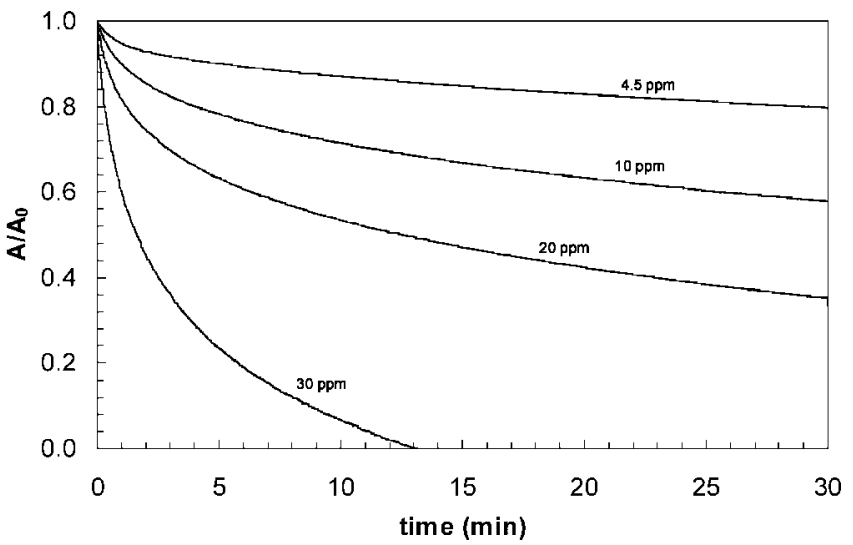

Fig. 1. Kinetics of consumption of triiodide complex $(\lambda=351 \mathrm{~nm})$ by HA and FA Gohy-573 at $\mathrm{pH}=5$ and $I=0.1 \mathrm{M} \mathrm{NaClO}_{4}$. 

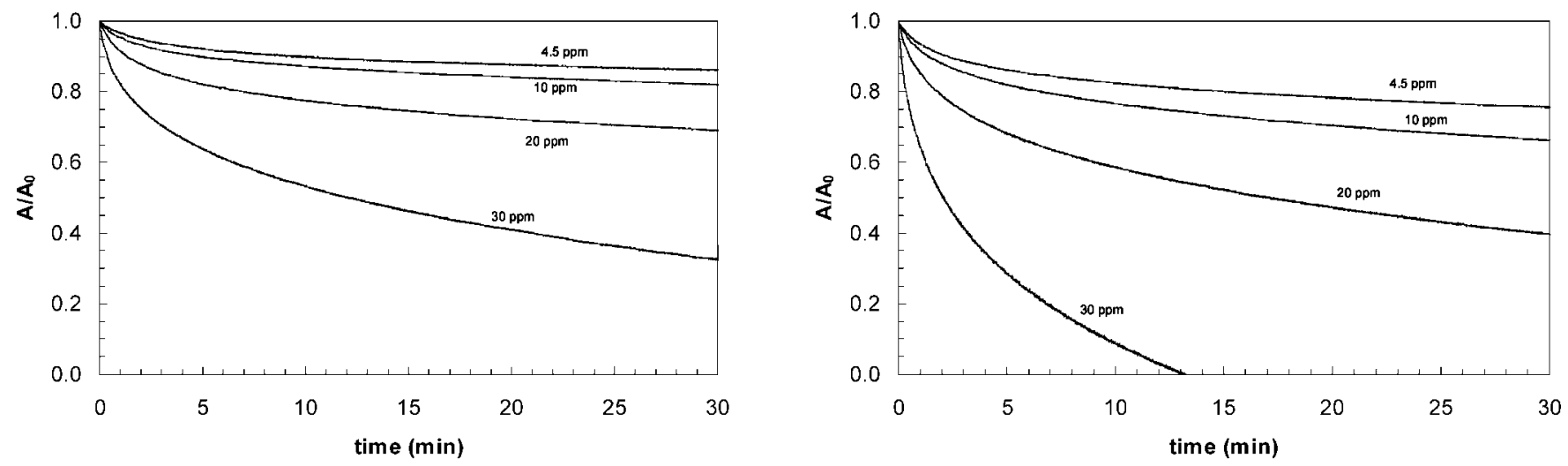

Fig. 2. Kinetics of consumption of triiodide $(\lambda=351 \mathrm{~nm})$ complex by synthetic $\mathrm{HA}$ at $\mathrm{pH}=5$ and $I=0.1 \mathrm{M} \mathrm{NaClO}_{4}$.

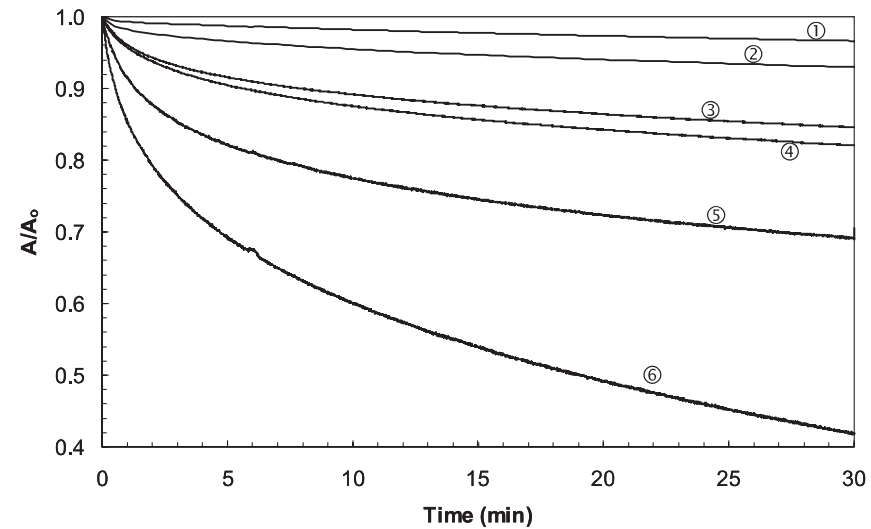

Fig. 3. Kinetics of triiodide complex consumption $(\lambda=351 \mathrm{~nm})$ by humic substances samples at $(\mathrm{HS})=20 \mathrm{mg} / \mathrm{L} \mathrm{pH}=5$ unless otherwise stated: (1) HA Aldrich [6], (2) FA Mol, $\mathrm{pH}=6$ [6], (3) FA Gohy 573 [this study], (4) HA Gohy 573 [this study], (5) M1 [this study], (6) M42 [this study].

Table 1. Elementary ratio for the different iodinated samples.

\begin{tabular}{ll}
\hline Sample & H/C \\
\hline Mol 15B & $0.98[38]$ \\
Aldrich & $0.97[39]$ \\
FA Gohy & $0.93[29]$ \\
HA Gohy & $0.92[29]$ \\
M1 & $0.89[30]$ \\
M42 & $0.87[30]$ \\
\hline
\end{tabular}

the decrease of the $\mathrm{H} / \mathrm{C}$ ratio, i.e. to the increasing aromaticity of the samples. The fact that of Mol 15B sample, which appears to be faster than Aldrich whereas its $\mathrm{H} / \mathrm{C}$ value is somewhat higher, is not surprising knowing that the kinetics has a negative order in $\left[\mathrm{H}^{+}\right]$, i.e. it increases with $\mathrm{pH}[6,17]$.

The decrease of $\mathrm{I}_{3}{ }^{-}$absorption bands in the near UV region during iodination experiment when $\mathrm{I}^{-}$is present has already been identified $[6,17]$. The release of $\mathrm{I}^{-}$due to the halogenation can also be evidenced in the UV region. The same experiment was performed firstly with Gohy$573 \mathrm{HA}(20 \mathrm{ppm})$ and $\mathrm{I}_{2}(\mathrm{aq})\left(10^{-4} \mathrm{M}\right)$ and no $\mathrm{I}^{-}$added in $\mathrm{NaClO}_{4}$ 0.1 M. Absorption spectra were acquired in the range 190-260 nm every 1.25 minutes (Fig. 4a). Absorption spectra represent the cumulative spectra of $\mathrm{I}_{2}(\mathrm{aq}), \mathrm{I}^{-}, \mathrm{I}_{3}{ }^{-}$
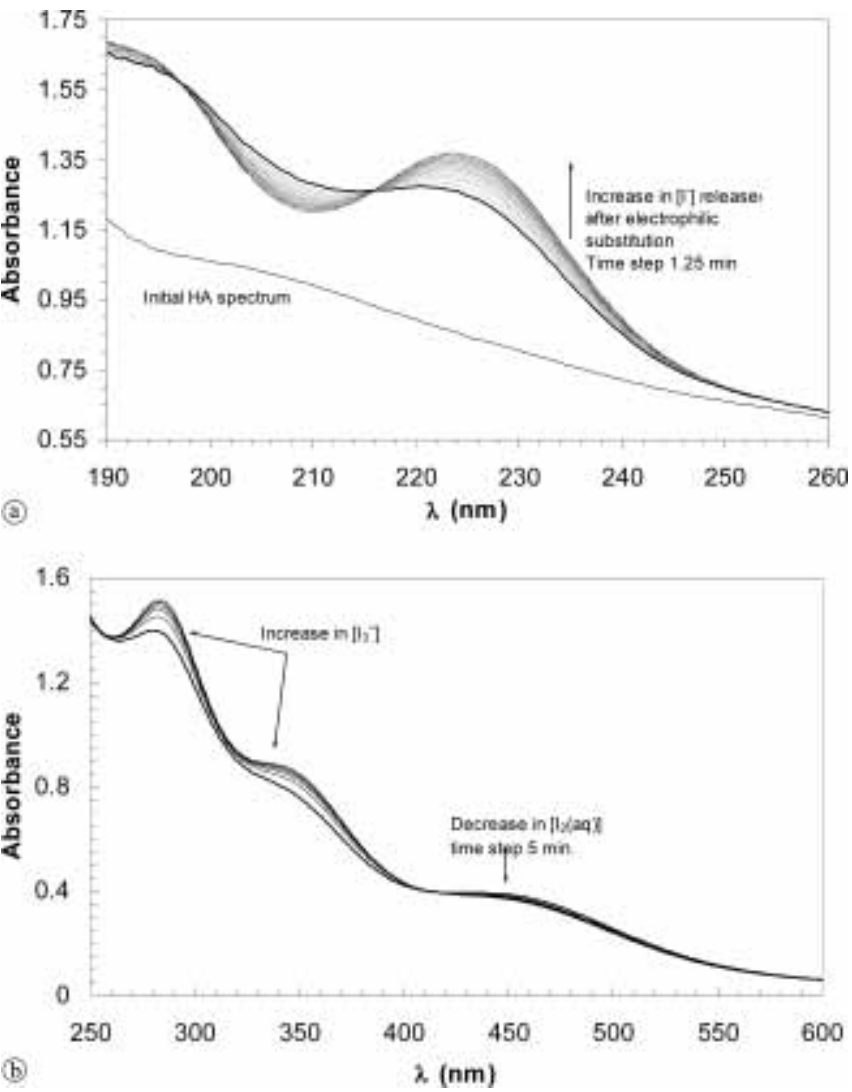

Fig. 4. UV-visible Spectra resulting from the reaction between Gohy-573 HA and $\mathrm{I}_{2}(\mathrm{aq})$ : $[\mathrm{HA}]=20 \mathrm{ppm}$; (a) $\left[\mathrm{I}_{2}(\mathrm{aq})\right]=10^{-4} \mathrm{M}$, (b) $\left[\mathrm{I}_{2}(\mathrm{aq})\right]=5 \times 10^{-4} \mathrm{M}$.

and HA. With time, absorbance at $\lambda \approx 230 \mathrm{~nm}$ increases representing the first $\mathrm{UV}$ band of $\mathrm{I}^{-}$formed during the reaction. This band is shifted by the absorption of HA itself. The second iodide UV-band at $\lambda \approx 190 \mathrm{~nm}$ also increases as the broad absorption band of $\mathrm{I}_{2}(\mathrm{aq})$ at $\lambda \approx 205 \mathrm{~nm}$ decreases resulting in two isobestic points at $\lambda \approx 196 \mathrm{~nm}$ and $\lambda \approx 216 \mathrm{~nm}$.

A second experiment was performed increasing the $\mathrm{I}_{2}(\mathrm{aq})$ concentration to $5 \times 10^{-4} \mathrm{M}$ and $\left[\mathrm{NaClO}_{4}\right]=0.1 \mathrm{M}$, and no added iodide. It can be seen on Fig. $4 \mathrm{~b}$ that not only the formation of $\mathrm{I}^{-}$can be evidenced but also the formation of the triiodide complex induced by the substitution reaction. Indeed, the kinetic is sufficiently low to let $\mathrm{I}^{-}$, produced by the substitution reaction, react with $\mathrm{I}_{2}(\mathrm{aq})$ in so- 

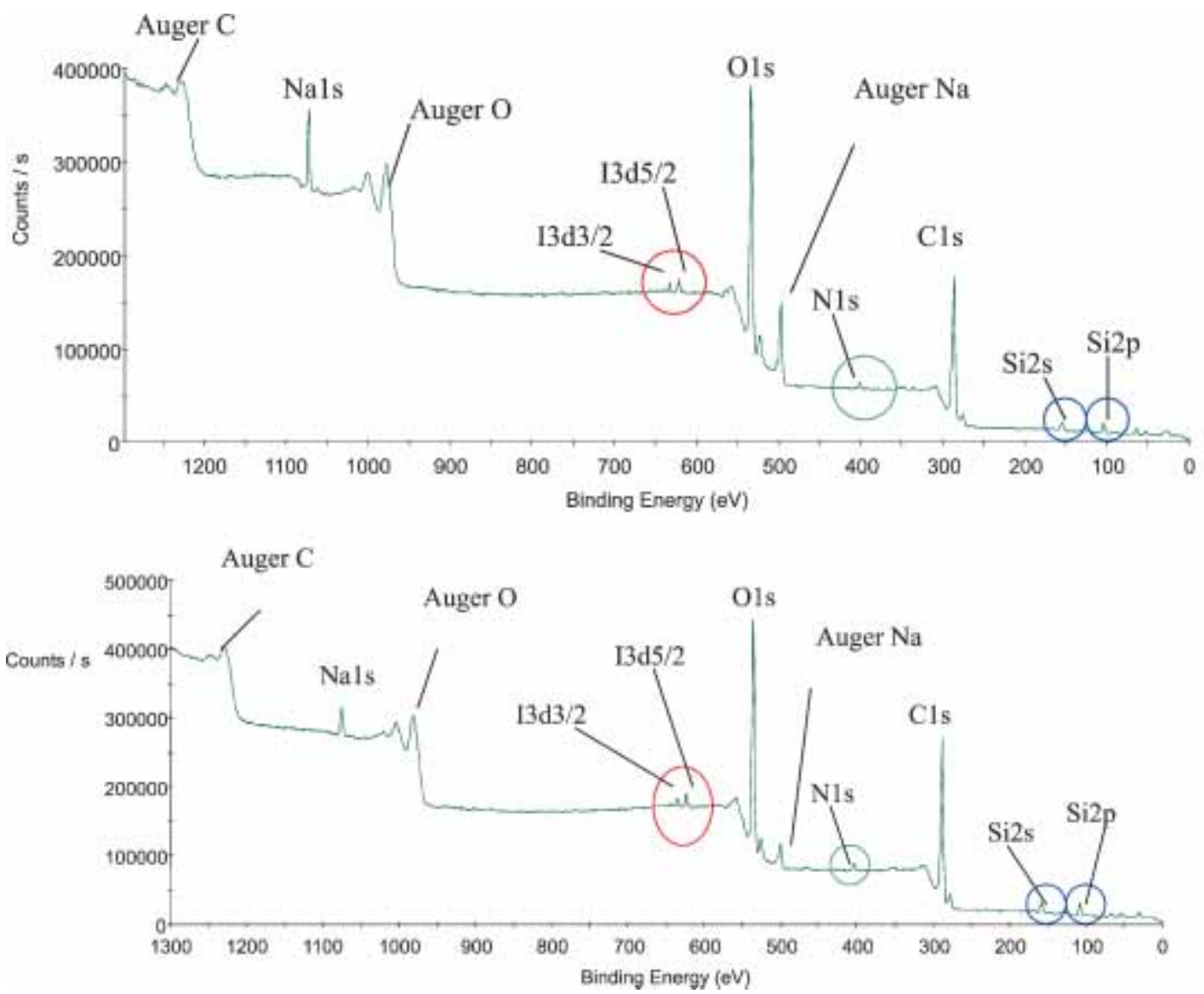

Fig. 5. Survey XPS spectrum of FA and HA from Gohy 573.
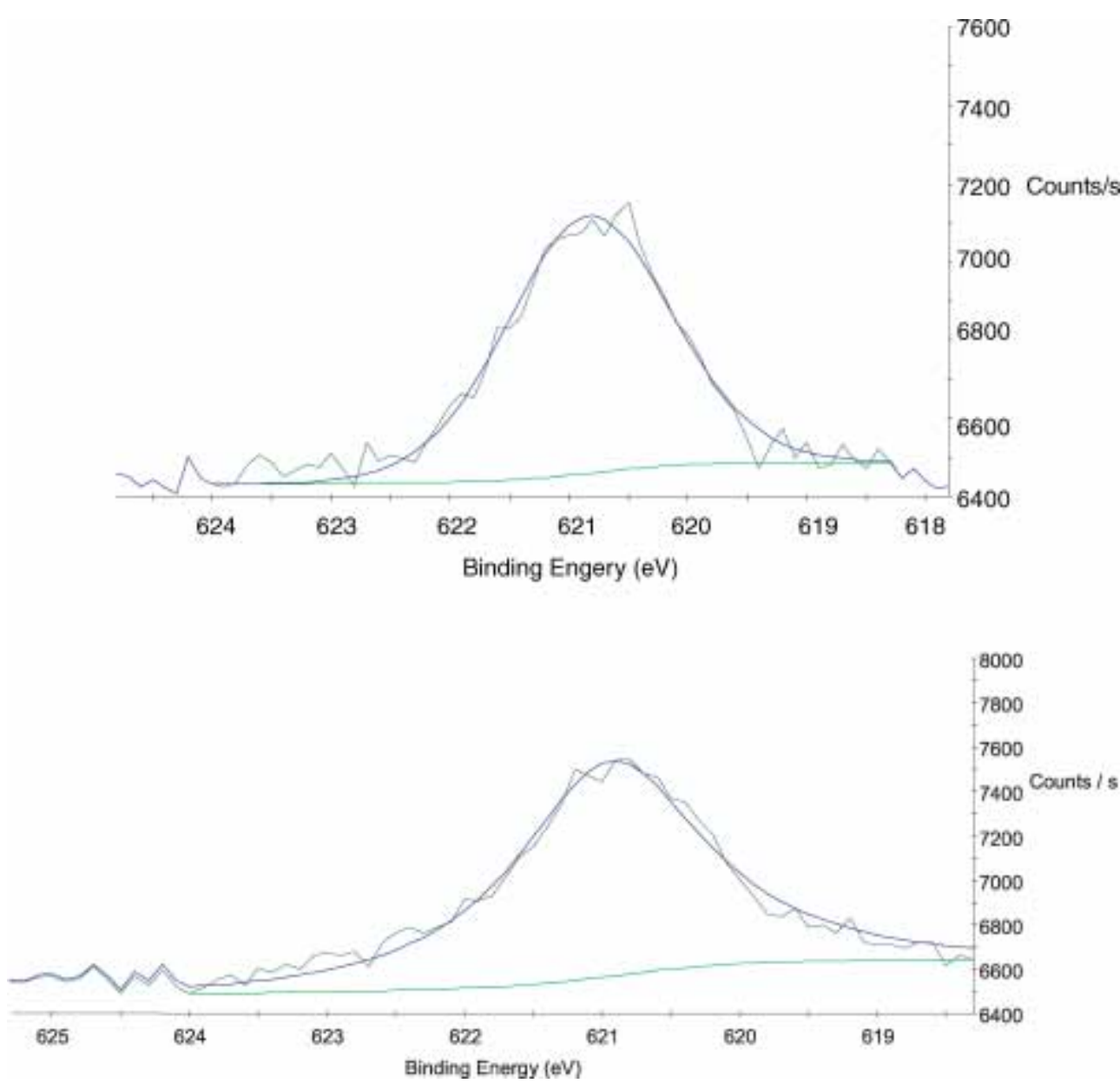

Fig. 6. $I_{3} d_{5 / 2}$ region of the FA (a) and HA (b) GOHY 573 contacted to diiodine. 
lution and form the triiodide complex. The two bands at $\lambda=351 \mathrm{~nm}$ and $\lambda=288 \mathrm{~nm}$, shifted by the presence of FA appear then clearly on Fig. 4b. Here again the increase in triiodide complex and the consumption of $\mathrm{I}_{2}(\mathrm{aq})$ result in an isobestic point at $\lambda=408 \mathrm{~nm}^{1}$.

Hence, the folloing mechanism is validated in the case of fulvic acid:

$$
\mathrm{I}^{-}+\mathrm{I}_{2}(\mathrm{aq}) \rightleftarrows \mathrm{I}_{3}^{-}
$$

The reaction pattern of iodine with HS is thus verified and seems to be general for all samples. In the following, only the Gohy and Synthetic samples will be used for XPS analysis in order to have a deeper insight into its chemical environment.

\subsection{X-ray photoelectron spectroscopy}

To determine the chemical environment of iodine, the $\mathrm{BE}$ position of the core-level region $\mathrm{I}_{3} d_{5 / 2}$ of iodine was followed for all the humic substances, such as natural humic substances Gohy 573 (Fulvic Acid FA), and synthetic humic acids M1 and M42 contacted to diiodine solutions. The iodine $3 d$ peaks were fitted with the software AVANTAGE (VG Instruments ${ }^{\circledR}$ ), using a Gaussian-Lorentzian peak shape after substraction of the background with a Shirley baseline.

The preparation of the binary system humic substances/ diiodine consists in the contact of $50 \mathrm{~mL}$ of $\mathrm{HS}$ (stock solution: HS powder dissolved in $\mathrm{NaOH}$ and prepared in $\mathrm{pH}=5$ solution of concentration $2 \mathrm{~g} / \mathrm{L}$ ) with $50 \mathrm{~mL}$ of a diiodine solution of concentration $10^{-3} \mathrm{~mol} \mathrm{~L}^{-1}$. The solutions were then dialysed against pure water $(3.5 \mathrm{kDa})$. The outer compartment was renewed until no $\mathrm{I}^{-}$could be detected in UV-visible spectrophotometry (limit of detection = $10^{-5} \mathrm{M}$ ). The UV-visible spectrum shape of dialysed Gohy 573 HS show no noticeable difference compared to the original one in the case of HA (data not shown), and only a slight difference in the case of FA.

Original Gorleben HS were already analyzed in XPS, and no iodine was detected $[34,35]$. The four humic substances samples contacted with diiodine were analyzed by XPS (humic and fulvic acids Gohy 573 and synthetic humic acids M1 and M42). As XPS is a solid investigation technique, the solution was progressively deposited on a glass slide and dried under hood until total solvent evaporation and sufficient covering of the surface.

The organic molecules and halogen compounds are known to be sensitive to the irradiation by the different beams and their characterization needs some care. In our experimental conditions, no obvious changes of the spectral features have been observed during the measurements, indicating the absence of radiation-induced damages.

Survey XPS spectra of Gorleben FA and HA are presented on Figs. 5a and b respectively. The major photoelectron peaks are attributed to carbon, nitrogen and oxygen. No metallic element can be detected in the samples except $\mathrm{Na}$ and $\mathrm{Si}$ probably both from glass slide and $\mathrm{NaOH}$, indicat-

\footnotetext{
${ }^{1}$ This isobestic point is shifted compared to the one which can be observed without HA at $\lambda=420 \mathrm{~nm}$ owing to their own absorbance.
}
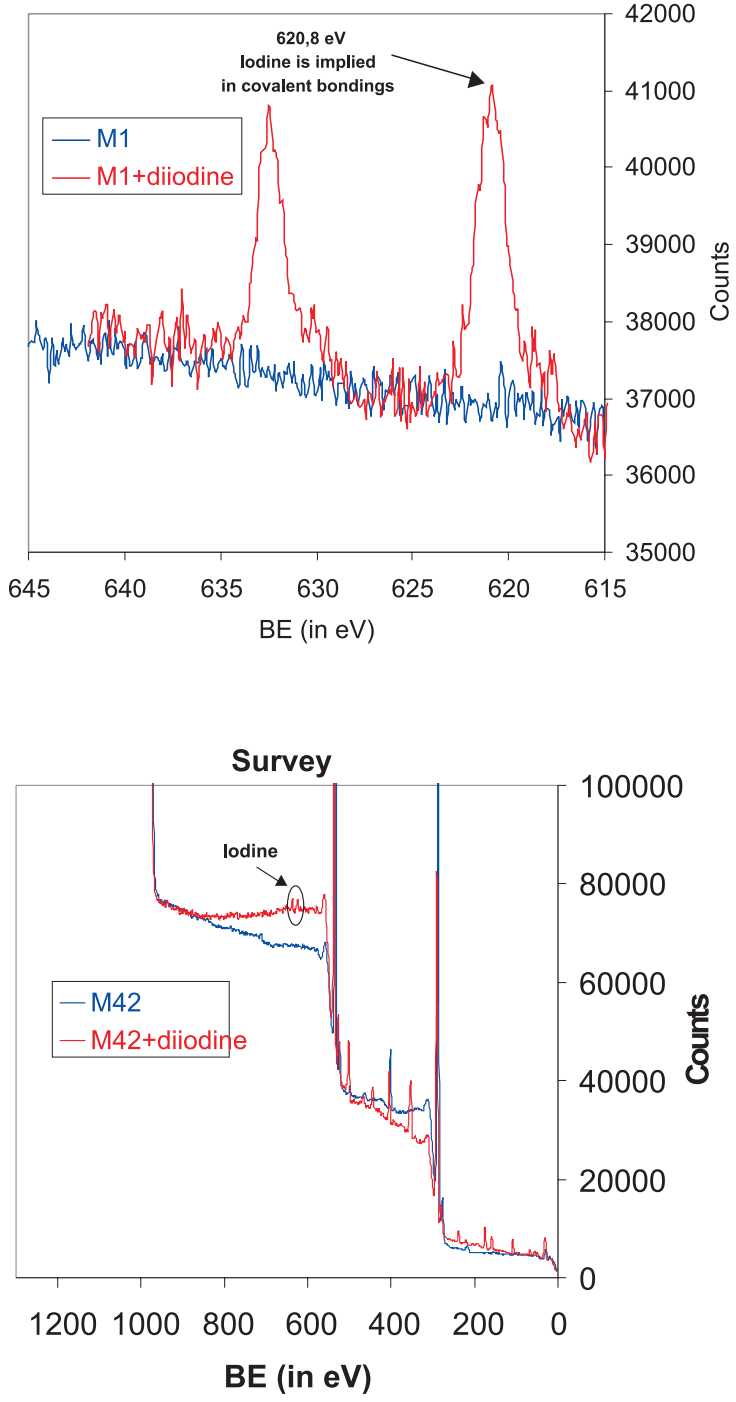

Fig. 7. Survey spectra of the M1 (a) and M42 (b) samples contacted to diiodine.

ing that these humic substances scavenge few cations or that these elements are present under the detection limit of XPS. All the samples revealed the presence of iodine, as shown by the obvious $\mathrm{I}_{3} d_{5 / 2}$ signal (Figs. 5 to 7 ), and in comparison to the same samples that were not contacted with diiodine solutions (see [34, 35] for Gohy samples and Fig. 7 for M1 and M42 samples).

Table 2. $\mathrm{I}_{3} d_{5 / 2}$ Binding energies.

\begin{tabular}{lcc}
\hline $\begin{array}{l}\text { Binding energies } \\
(\mathrm{eV}) \mathrm{I} 3 d^{5 / 2}\end{array}$ & & References \\
\hline 618.2 & $\mathrm{NaI}$ & \\
618.5 & $\mathrm{KI}$ & \\
619.5 & $\mathrm{LiI}$ & \\
618.3 & $\mathrm{NaI}$ & \\
618.4 & $\mathrm{KI}$ & \\
619.1 & $\mathrm{LiI}$ & \\
$619.3 / 619.7$ & $\mathrm{KI}$ & \\
$620 / 621.4$ & Different iodinated \\
$618 / 621$ & organic compounds Naturally \\
$623.5 / 624$ & iodinated FA KIO & \\
\hline
\end{tabular}


Even if the signal to noise ratio of the $\mathrm{I}_{3} d_{5 / 2}$ peaks is relatively weak, the deconvolution of the $\mathrm{I}_{3} d_{5 / 2}$ peak indicates a single major contribution for each of the samples, owing to the symmetry and the FWMH of the photoelectron peak. The BE value of the characteristic $\mathrm{I}_{3} d_{5 / 2}$ peak for an iodine atom implying iodide $(\mathrm{BE} \approx$ $619.3-619.7 \mathrm{eV})$ iodate $(\mathrm{BE}=623.5-624 \mathrm{eV})$ and for organic molecules $(\mathrm{BE}=620-621.4 \mathrm{eV})$ have already been determined [20, 21, 36, 37] (see Table 2). Hence, for the FA and HA samples, the major contribution at $620.8 \mathrm{eV}$ permits us to exclude the presence of either I(V) or I(-I). This verifies the results obtained in UV-visible of iodinated samples after dialysis. These results further confirm that iodine atoms are linked by covalent bonding in natural organic matter [19-23]. As XPS is not a trace element analysis technique, the presence of iodine revealed in the humic substances samples suggests that the proportion of organically bound iodine is more than the detection limit, i.e. $1 \%$ in mass for iodine.

\section{Conclusion}

These results confirmed that iodine can be fixed to HS through covalent bonding, from natural to synthetic samples. Even if iodination kinetics could neither be correlated linearly to $\left[\mathrm{H}^{+}\right]$nor to the $\mathrm{HS}$ concentration, the $\mathrm{H} / \mathrm{C}$ ratio, and thus the aromaticity of the sample, has been identified as a key factor. The UV-visible analysis clearly showed that the consuming of molecular iodine leads to the formation of iodide and triiodide complex confirming the electrophilic substitution mechanism.

Hence, through this study it is suggested that combination of techniques, such as UV-visible and XPS, can bring complementary information even on complicated systems such as iodine and HS, in terms of mechanism elucidation and XPS characterisation of organic matter and halogens.

Acknowledgment. This work has been carried out in the framework of the "HUPA project" (EC: FIKW-CT-2001-00128), and MRTRA project of the Risk Control Domain of CEA (CEA/DEN/DDIN).

\section{References}

1. Ashmore, C. B., Gwyther, J. R., Sims, H. E.: Some effects of pH on inorganic iodine volatility in containment. Nucl. Eng. Des. 166, 347 (1996).

2. Luckett, L. W., Stotler, R. E.: Radioiodine volatilization from reformulated sodium iodide I-131 oral solution. J. Nucl. Med. 21, 477 (1980).

3. Frechou, C., Calmet, D., Bertho, X., Gaudry, A.: ${ }^{129} \mathrm{I} /{ }^{127} \mathrm{I}$ ratio measurements in bovine thyroids from the north cotentin area (France). Sci. Total Environ. 293, 59 (2002).

4. ANDRA: Dossier 2005. Argile. Tome Evolution phénoménologique du stockage géologique. ANDRA, Report (2005), http://www.andra.fr/publication/produit/D05A_269_TEP.pdf.

5. Andersen, S., Petersen, S. B., Laurberg, P.: Iodine in drinking water in Denmark is bound in humic substances. Eur. J. Endocrinol. 147, 663 (2002).

6. Reiller, P., Moulin, V.: Influence of organic matter in the prediction of iodine migration in natural environment. Mater. Res. Soc. Symp. Proc. 757, 565 (2003).

7. Ashworth, D., Shaw, G., Butler, A., Ciciani, L.: Soil transport and plant uptake of radio-iodine from near-surface groundwater. J. Environ. Rad. 70, 99 (2003).
8. Tessier, E., Amouroux, D., Abril, G., Lemaire, E., Donard, O. F. X.: Formation and volatilisation of alkyl-iodides and -selenides in macrotidal estuaries. Biogeochemistry 59, 183 (2002).

9. Yamada, H., Hisamori, I., Yonebayashi, K.: Identification of organically bound iodine in soil humic substances by size exclusion chromatography/inductively coupled plasma mass spectrometry (SEC/ICP-MS). Soil Sci. Plant Nutr. 48, 379 (2002).

10. Yamada, H., Kiriyama, T., Onagawa, Y., Hisamori, I., Miyazaki, C., Yonebayashi, K.: Speciation of iodine in soils. Soil Sci. Plant Nutr. 45, 563 (1999).

11. Pedersen, K. M., Laurberg, P., Nohr, S., Jorgensen, A., Andersen, S.: Iodine in drinking water varies by more than 100 -fold in Denmark. Importance for iodine content of infant formulas. Eur. J. Endocrinol. 140, 400 (1999).

12. Bostock, A. C., Shaw, G., Bell, J. N. B.: The volatilisation and sorption of I-129 in coniferous forest, grassland and frozen soils. J. Environ. Rad. 70, 29 (2003).

13. Francois, R.: The influence of humic substances on the geochemistry of iodine in nearshore and hemipelagic marine sediment. Geochim. Cosmochim. Acta 51, 2417 (1987).

14. Lee, C. F.: In: Kinetics of Reactions Between Chlorine and Phenolic Compounds. Principles and Applications of Water Chemistry Proceedings. (Faust, S. D., Hunter, J. V., eds.) Wiley, New York (1967) p. 54.

15. Gallard, H., von Gunten, U.: Chlorination of phenols: Kinetics and formation of chloroform. Environ. Sci. Technol. 36, 884 (2002).

16. Bichsel, Y., von Gunten, U.: Formation of iodo-trihalomethanes during disinfection and oxidation of iodide-containing waters. Environ. Sci. Technol. 34, 2784 (2000).

17. Warner, J. A., Casey, W. H., Dahlgren, R. A.: Interaction kinetics of $\mathrm{I}_{2}(\mathrm{aq})$ with substituted phenols and humic substances. Environ. Sci. Technol. 34, 3180 (2000).

18. Moulin, V., Reiller, P., Amekraz, B., Moulin, C.: Direct characterization of iodine covalently bound to fulvic acids by electrospray mass spectrometry. Rapid Commun. Mass Spectrom. 15, 2488 (2001).

19. Mercier, F., Moulin, V., Barré, N., Trocellier, P., Toulhoat, P.: Study of a ternary system silica/humic acids/iodine: capabilities of the nuclear microprobe. Nucl. Instrum. Method. Phys. Res. B 181, 628 (2001).

20. Mercier, F., Moulin, V., Guittet, M. J., Barré, N., Toulhoat, N., Gautier-Soyer, M., Toulhoat, P.: Applications of NAA, PIXE and XPS for the quantification and characterization of the humic substances/iodine associations. Radiochim. Acta 88, 779 (2000).

21. Mercier, F., Moulin, V., Guittet, M. J., Barre, N., Gautier-Soyer, M., Trocellier, P., Toulhoat, P.: Applications of new surface analysis techniques (NMA and XPS) to humic substances. Org. Geochem. 33, 247 (2002).

22. Schlegel, M. L., Mercier, F., Barre, N., Reiller, P.: Iodine speciation in iodine-rich humic substances by X-ray absorption spectroscopy. Geochim. Cosmochim. Acta 68, A362 (2004).

23. Schlegel, M. L., Reiller, P., Mercier-Bion, F., Barré, N., Moulin, V.: Molecular environment in naturally iodinated humic substances: insights from X-ray absorption spectroscopy. Geochim. Cosmochim. Acta (accepted).

24. Nefedov, V., Teterin, Y., Lebedev, A., Teterin, A., Dementjev, A., Bubner, M., Reich, T., Pompe, S., Heise, K., Nitsche, H.: Electron spectroscopy for chemical analysis investigation of the interaction of uranyl and calcium ions with humic acids. Inorg. Chim. Acta 273, 234 (1998)

25. Schild, D., Marquardt, C. M.: Analysis of Th(IV)-humate by XPS. Radiochim. Acta 88, 587 (2000).

26. Monteil-Rivera, F., Brouwer, E. B., Masset, S., Deslandes, Y., Dumonceau, J.: Combination of X-ray photoelectron and solid-state C-13 nuclear magnetic resonance spectroscopy in the structural characterisation of humic acids. Anal. Chim. Acta 424, 243 (2000).

27. Schild, D., Marquardt, C., Seibert, A. Analysis of Pu-Humate by XPS. 9th International Conference on Chemistry and Migration Behavior of Actinides and Fission Products in the Geosphere, Migration '03, Gyeongju, Korea, September 21-26 (2003).

28. Bernede, J., Taoudi, H., Bonnet, A., Molinie, P., Morsli, M., De Valle, M., Diaz, F.: XPS and ESR studies of electrochemically 
synthesized polycarbazole post-doped with iodine. J. Appl. Polym. Sci. 71, 115 (1999).

29. Wolf, M., Buckau, G., Geyer, S.: Isolation and characterization of new batches of Gohy-573 humic and fulvic acids. In: Humic Substances in Performance Assessment of Nuclear Waste Disposal: Actinide and Iodine Migration in the Far-Field. Second Technical Progress Report (Buckau, G., ed.) FZK-INE, Report FZKA 6969, http://bibliothek.fzk.de/zb/berichte/FZKA6969.pdf, Karlsruhe (2004) p. 111.

30. Sachs, S., Heise, K. H., Bernhard, G.: Synthetic Humic Acid Model Substances with Specific Functional Properties for the Use in Complexation and Sorption Experiments with Actinides. In: Humic Substances in Performance Assessment of Nuclear Waste Disposal: Actinide and Iodine Migration in the Far-Field. First Technical Progress Report (Buckau, G., ed.) FZK-INE, Report FZKA 68000,

http://bibliothek.fzk.de/zb/berichte/FZKA6800.pdf, Karlsruhe (2003) p. 51.

31. Kumke, M. U., Specht, C. H., Brinkmann, T., Frimmel, F. H.: Alkaline Hydrolysis Of Humic Substances - Spectroscopic And Chromatographic Investigations. Chemosphere 45, 1023 (2001).

32. Ramette, R. W., Sandford, R. W.: Thermodynamics Of Iodine Solubility And Triiodide Ion Formation In Water And In Deuterium Oxide. J. Am. Chem. Soc. 87, 5001 (1965).

33. Benedetti, M. F., Van Riemsdijk, W. H., Koopal, L. K.: Humic Substances Considered As A Heterogeneous Donnan Gel Phase. Environ. Sci. Technol. 30, 1805 (1996).
34. Barré, N., Mercier-Bion, F., Reiller, P.: X-Ray Photoelectron Spectroscopy Of Hupa Organic Substances: Natural and Synthetic Humic Compounds. In: Humic Substances in Performance Assessment of Nuclear Waste Disposal: Actinide and Iodine Migration in the Far-Field. Second Technical Progress Report (Buckau, G., ed.) FZK-INE, Report FZKA 6969, http://bibliothek.fzk.de/zb/berichte/FZKA6969.pdf, Karlsruhe (2004) p. 125.

35. Reiller, P., Mercier, F., Gimenez, N., Barre, N., Miserque, F.: Iodination of the humic samples from HUPA project. In: Humic substances in performance assessment of nuclear waste disposal: actinide and iodine migration in the far-field. Third technical report (Buckau, G., ed.) FZK-INE, Report FZKA 7070, http://bibliothek.fzk.de/zb/berichte/FZKA7070.pdf, Karlsruhe (2005) p. 47.

36. Wagner, C. D., Riggs, W. M., Davis, L. E., Moulder, J. F.: Handbook of X-ray Photoelectron Spectroscopy. Perkin-Elmer Corporation (Physical Electronics) (1979).

37. Briggs, D., Seah, M. P.: Practical Surface Analysis - Auger and X-ray Photoelectron Spectroscopy. Wiley, New York (1990).

38. Montjotin, C.: Isolation, caractérisation et mesures des teneurs en 14 de substances humiques aquatiques: application à la datation des eaux souterraines. Ph. D Thesis, Université d'Orsay, Paris Sud, Orsay (1996).

39. Kim, J. I., Buckau, G., Klenze, R., Rhee, D. S., Wimmer, H.: Characterisation and complexation of humic acids. Commission of the European Communities, Report EUR 13181, Brussels (1991).

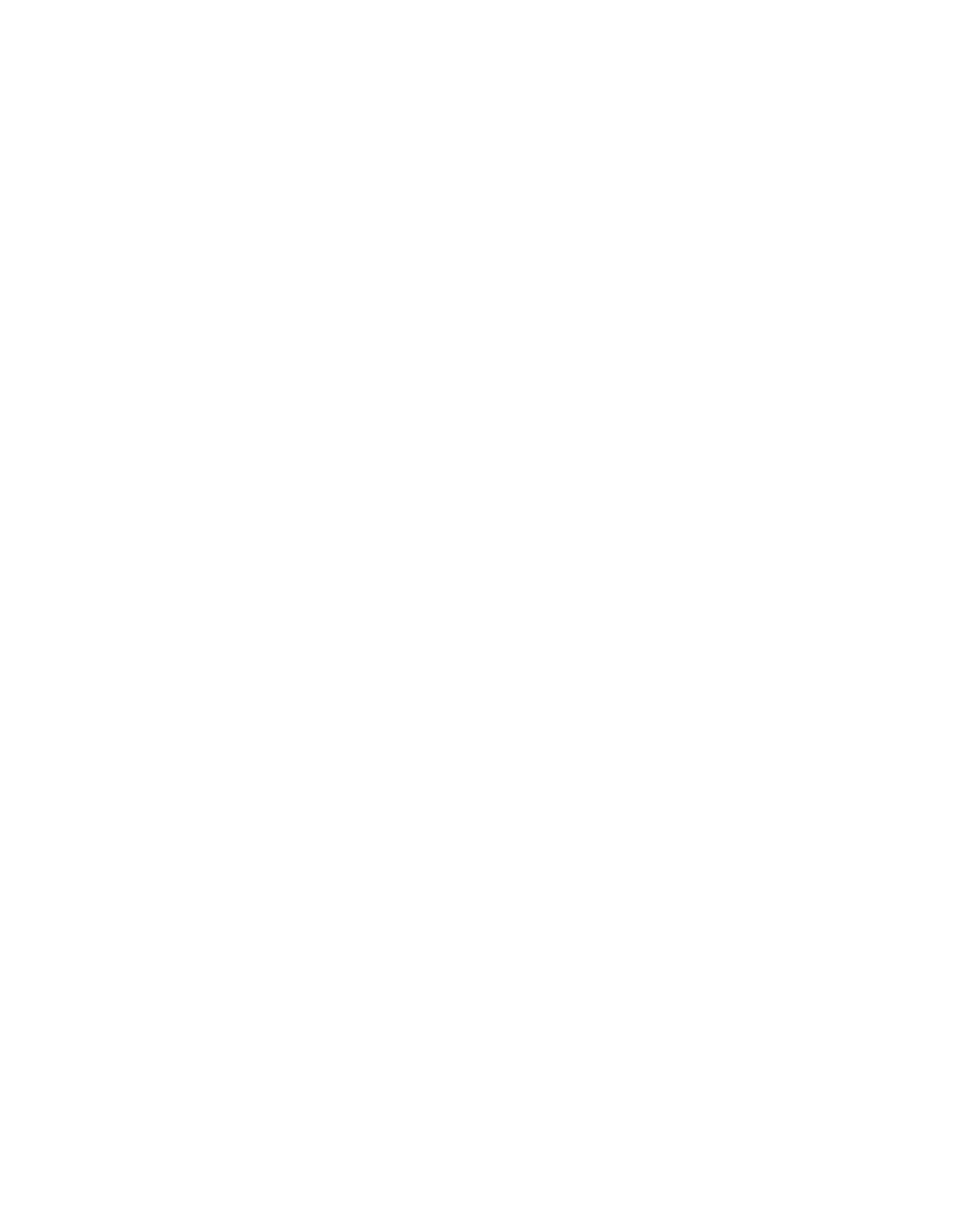

